\title{
Teaching English Components. To Young Learners
}

\author{
Siwi Karmadi Kurniasih \\ State University of Yogyakarta
}

\begin{abstract}
Teaching English for children requires thoughtful considerations of what and how to teach. It needs full considerations such as what components of the language should be taught, what method should be applied, and what teaching technique should be employed.

Teaching English components i.e. grammar, vocabulary, and pronunciation, a teacher must take the nature of children leaming into account. Teaching vocabulary, teacher should plan and organize the material to leam carefully. Concrete objects should come before the abstract ones. Teaching vocabulary is not only about teaching words as separate units but formulaic chunks. In addition, teaching strategies play an important role in children's learning success.

Leaming grammar is closely related to learning vocabulary. When children learn vocabulary through learning formulaic chunks, the teacher can discuss the grammar too. One important thing that teacher should bear in her mind is that the opportunity to use the language in a meaning-focused situation is as important as learning the grammatical patterns.

The other language component to leam is pronunciation. As the other components, teaching pronunciation to young leamers also need thoughtful consideration. Normally native speakers say an expression in blended sounds. They will not say each word clearly as separate unit. Hence, teachers should drill students to say expressions and guide students to feel and experience saying them in normal and natural way.
\end{abstract}

Keywords: teaching English, young learners 


\section{A. Introduction}

Why should children learn English in Indonesia where they will not need. English to survive in the community? Do they really need it at their age? What language components should teachers teach the children? What actually the ultimate need is in learning English for young learners? Which one is the most important and should be prioritized: vocabulary, grammar, or pronunciation? How are they to be organized and delivered in class? Should they all come altogether in an integrated course or be given discretely? These questions may have been stored at the back of every teacher's mind. So many other questions bombard teachers when planning English course for children especially it is as a foreign language.

Without grammar very little can be conveyed, without vocabulary nothing can be conveyed (Wilkins in Thombury 2002). We may share the same belief as Wilkins does. Indeed, vocabulary is one important component of English that children should learn in order that they can use English words properly to get a message across or at least to understand English contexts. However, the other English components i.e. pronunciation and grammar are just as important as vocabulary. To have good command of English, a learner has to have good grammar and pronunciation, and sufficient vocabulary. The problem is how the teacher should teach and help the students master those language components.

The theory of language acquisition postulates guidance about what a child does and does not do when learning or acquiring a language (Fromkin, et al., 1996):

1. Children do not learn a language by storing all the words and all the sentences in some giant mental dictionary. The list of words is finite, but no dictionary can hold all the sentences, which are infinite in number.

2. Children learn to construct sentences, most of which they have never produced before.

3. Children learn to understand sentences they have never heard before. They cannot do so by matching the heard utterance with some stored sentence.

4. Children must therefore construct the 'rules' that permit them to use their language creatively.

5. No one teaches them these rules. Their parents are no more aware of the phonological, morphological, syntactic, and semantic rules than are the children. 


\section{B. Teaching.Vocabulary}

Before discussing how to teach children vocabulary,-it-is necessary to discuss what vocabulary is. Generally; laypeople regard vocabulary as a group of words that have meanings and are listed in dictionary. Word is not easy to define (Read, 2000; Singleton, 1999 in Cameron, 2001), though. Discussing vocabulary, we need to talk about some vocabulary-related terms such as type and token, function word and content word, lexical item, word family, collocation, idioms, etc. Therefore, teachers need to decide to what extent children should learn vocabulary and its related aspects. Another consideration is the nature of children learning" vocabulary. Children learn a word by asking what a particular word means, or how to say a word in the foreign language, and the word is a key unit in building up skills and knowledge when they learn to read (Cameron, 2001).

To start with, let us discuss what a learner should know about a word if they are to acquire it completely. Richards suggested thatknowing a word means:

1. knowing the degree of probability of encountering that word in speech or print.

2. knowing the limitations on the use of the word according to variations of function and situation.

3. knowing the syntactic behavior associated with the word.

4. entails knowledge of the underlying form of a word and the derivations that can be made from it.

5. entails knowledge of the network of associations between that word and other words in the language.

6. knowing the semantic value of a word.

7. knowing many of the different meanings associated with a word.

- (Richards, 1976: 83 in Read, 2000: 25)

As suggested by Brewster (2004), the teacher will guide the children going through five stages in learning new words and attaching these to words they already know. The five stages are: 1) understanding and learning the meaning of new words; 2) attending to form; 3 ) vocabulary practicing, memorizing, and checking activities; 4) consolidating, recycling, extending, organizing, recording, and personalizing vocabulary; and 5) developing strategies for vocabulary learning. 
Mastering all those tasks, students are expected to have a good command of the language i.e. English. Further, Nation suggests some teaching vocabulary principles that teacher should bear in mind:

1. Keep the teaching simple and clear. Do not give complicated explanations.

2. Relate the present teaching to past knowledge by showing a pattern or analogies.

3. Use both oral and written presentation - write it on the blackboard as well as explaining.

4. Give most attention to words that already have been partly known.

5. Tell the leamers if it is a high frequency word that is worth noting for future attention.

6. Do not bring in other unknown or poorly known related words like near synonyms, opposites, or members of the same lexical set.

\section{Learning vocabulary in class}

Children start learming words in their mother tongue with naming objects. Thus, 'nouns' are usually introduced earlier than the other parts of speech. Considering the fact, teacher can start a course by introducing 'concrete nouns' that they can feel, play, and experience in teaching children at the early stages. Teacher can bring to the class pictures, puppets, or dolls as the teaching media. Realia is another good choice as the students can see and feel the real thing they are learning, for example, when the students are learning names of fruit and vegetables the teacher can bring them along to class. The things in their surroundings may come in handy as well. For instance, when students leam the names of school equipments they can name the objects around them in the classroom.
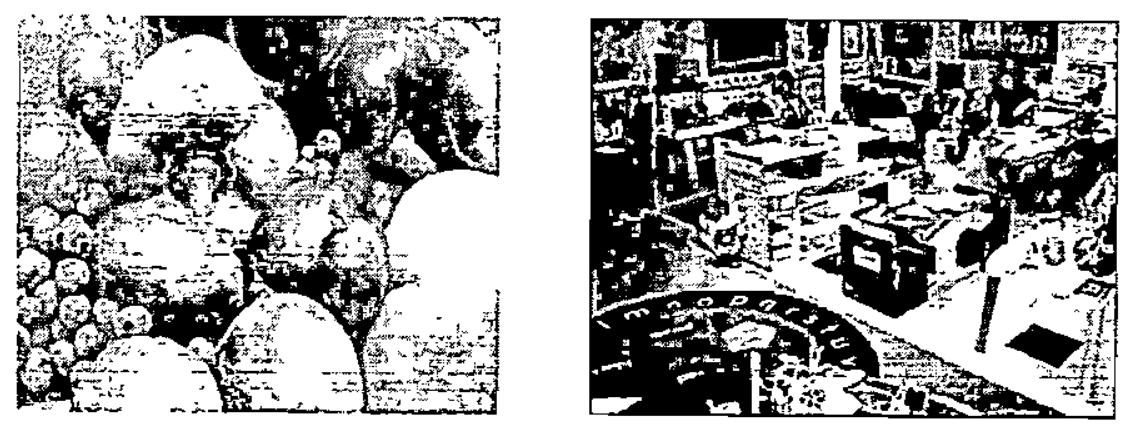
Children develop their ability to say the word first without having full understanding of the meaning of the-word (Locke, 1993 in Cameron 2001). The understanding develops later. Along the childhood, children use words that they partially understand. The development continues to not only add the number of the words but also build up the knowledge about the words they already partially know.

Vocabulary development is about learning words, about learning formulaic phrases or chunks, finding words inside them, and learning even more about those words (Cameron, 2001). Hearing certain expressions repeatedly, children tend to imitate them even when they have no idea what the words or expressions mean, or how the sentence is constructed. "I don't know," is probably the expression they are familiar with and they produced in real life setting with precise use even though they have not learnt how the construction is produced.

Children's tearning foreign vocabulary comes along with their learning first language since children in their early years are building up their first language vocabulary. Some of the foreign words they learn may link to the first language words they have fully understood and formed. Many others, on the other hand, may not link one another due to the different culture or other aspects. Therefore, teachers should not introduce things that students will rarely encounter in their daily life at early stages. Take, when students in Indonesia learn names of fruit and vegetable they do not need to know plum, peach, artichoke, or radish at early stages. The point is that learning foreign vocabulary needs long process. Children need to encounter the foreign words over the time along with the first language development. By the time they fully develop the first language, they can bring the conceptual knowledge to the vocabulary to the foreign language words they learn. The root system of word knowledge continues to grow and become more tightly inter-linked. Therefore in planning and teaching foreign language, we have to take into account this first language background (Cameron, 2001). The consideration will tell us what the children will learn easily and what they will find difficult to learn. Cameron (2001) suggests the realistic number of words for children to learn in a year is 500 words in good learning condition.

As discussed_earlier, the conceptual knowledge grows as children grow and get more and more experience in the use of language. Cameron states that maturational factors play role in the conceptual knowledge about the first language that can be expected to have a knock-on effect for foreign language leaming. In 
younger age, a child tends to link a word with other words from different part of speech with the same 'theme'. For example, when children are given a cue word 'cat', they will associate it with 'meow' or 'cute'. Later, when they grow older and have more experience they more likely to link the cue word with 'animal' or 'pet', which has the same part of speech.

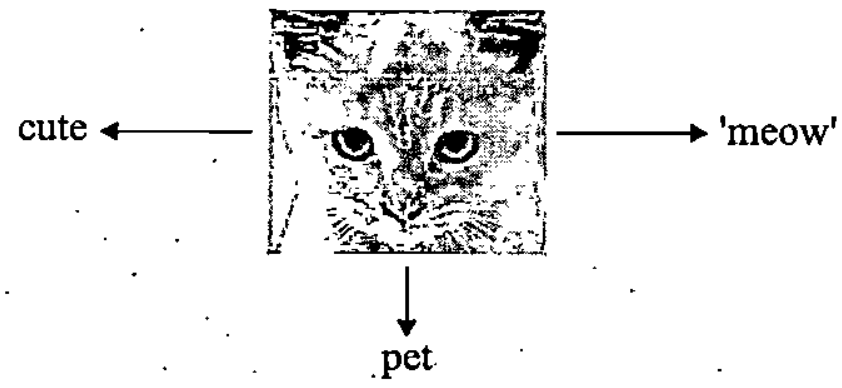

Considering children's nature that they easily forget what they have learned, teacher should re-present the vocabulary that they have learned in different situations. Some techniques can be employed such as games, projects, and TPR. The same teaching materials can be used more than once with certain modifications to recycle the use of the previous vocabulary. Concentration game using pictures and words will be interesting for younger children. The students are supposed to match between pictures and words. The same pictures can be used again later when the class learn colors. The teacher can make the picture black and white for the students to color based on the teacher's instructions.

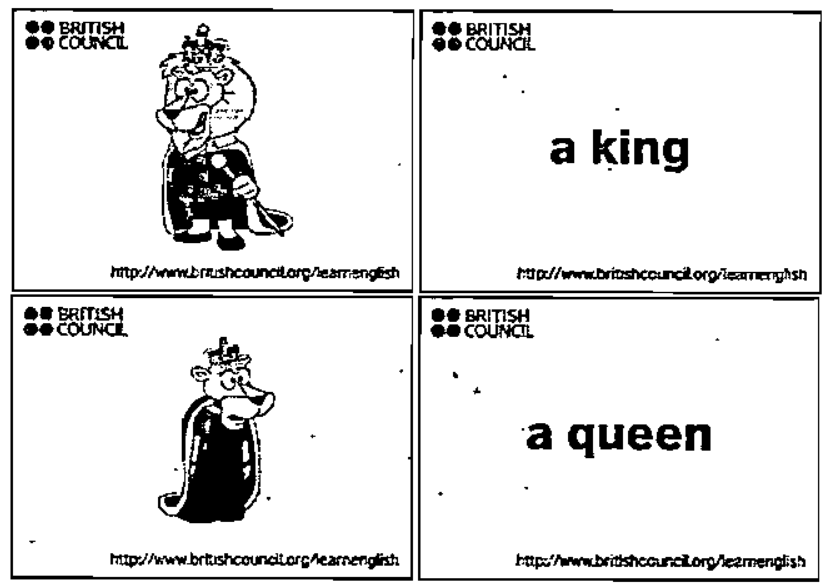

The-cards were-retrieved from www.britishcouncil.org/leaningenglish on August 17, 2009 
Using TPR, children practice to listen to the new language and respond it nonverbally. Besides, to give opportunities for deep processing of vocabulary, we can teach students how to use dictionaries and have them keep vocabulary notebooks (Linse and Nunan (ed.), 2005). .

\section{Teaching Grammar}

Why should children know grammar? It may be the most often raised question. We may believe that what the children should know is how to communicate, and what they need will be words not grammar. When a child wants to get a pencil, he can simply say 'pencil'. He does not need to have a complete sentence 'Can I have a pencil?' to get the same result. Considering the fact, many teachers believe that they should not teach grammar to children; that it is too difficult for children.

It is true that at the basic level children are not yet capable of producing complete sentences but words. Nonetheless, vocabulary and grammar are interdependent; every word carries grammatical information in it, as it is not used in isolation. The more someone leams vocabulary, the more grammatical knowledge he/she gets, the more difficult both vocabulary and grammar to be split up. It means that if we leam vocabulary, unconsciously we also leam grammar. For example, when we learn the verb 'go', we have to know other related words such as the preposition follows the verb i.e. 'to', or the past tense form 'went', or past participle form 'gone'. Of course, primary students will not learn them all at once.

Despite the difficulty it may create, still English teacher needs to teach grammar. Wilson and Scanlon (2005) convinced us that teacher has to teach grammar since it helps children in their language skill deyelopment.

One of the most difficult but most important tasks for primary teachers is to ensure that they pass on knowledge of grammar to children in such a way that it helps to make the children more discriminating readers, writers and speakers and empowers them to produce written and spoken texts which both embody what it is they want to say and make a suitable impact on those listening or reading.

Moreover, Cameron (2001), tries to convince us that grammar does bave a place in children's foreign language leaming. These are some considerations in teaching-learning grammar for young children as posted by Camèron: 
- grammar is necessary to express precise meanings in discourse;

- grammar ties closely into vocabulary in learning and using the foreign language;

- grammar learning can evolve from the learning of chunks of language;

- talking about something meaningful with the child can be a useful way to introduce new grammar;

- grammar can be taught without technical labels.

Language is dynamic; it changes all the time. It does not exist as an object; separate from the people as the producers, performers, and users. The dynamism is obvious in teenagers' language use where new words are invented and new ways of talking come and go in days. Thereby, we need to set fix rules so that English is understandable for learners and there are rules to follow. Breaking a language into pieces in word-size produces vocabulary and the formulating of patterns in how words are put together produces grammar. The patterns called as rules; these rules are formulated in a way that it refers to what people usually do, not what teachers must obey (Cameron, 2001).

Since by the time children learn a foreign language they have limited amount of data to work on, so that they find it difficult to deal with the foreign language grammatical rules. Children will tend to turn to their first language to fill the gap. Moreover, the rules will more likely be over-generalized or incomplete, for example, the formation of past verbs such as 'goed' for 'went'.

They way children develop a language is not merely through imitation or analogy. Data show that children make non-random mistakes and they have the ability to learn language without any formal instruction. In addition, the way children learn foreign language is more or less goes through.similar phases as they learn their mother tongue. In developing their first language, children do not develop in exactly the same stages but they are similar. Children's language progresses from simple to more complex rules, as is shown below (Fromkin, et al, 1996:331):

One word stage: single negative word

First sentences: Negative word added to beginning of sentence

Later sentences: Negative element inserted between subject and predicate.
No.

No want food.

He no bite you. 
-Negative auxiliaries don't, can't appear.

Negation 'spread' some becomes no.

negative element inserted correctly I don't want any food.
I can't catch you.

- Fraser don't want no food. no changed to any.

Lewis in Brewster (2004) breaks down grammar into three accessible and manageable categories:

- Facts: there are many exceptions in English grammar such as irregular past form of verb, irregular plural nouns that children can only accept for what they are and leam them.

- Patterns: teacher should help children to be aware of the language pattern. Understanding the pattern, children will be able to construct new sentences themselves. For example, Ilike (ice cream/candies/cakes).

- Choices: A grammatical structure to be used to express an idea is personal choice. We can say either I have drawing since I was 5 or I have been drawing since I was 5.

\section{E. Learning Grammar in Class}

One way to teach grammar for children is through formulaic phrases or chunks. The strategy can both develop communicative skills and grammar mastery (Weinert in Brewster, 2004). Chunks, learned by rote, are sometimes split up into parts and combined or substituted with other words in a sentence. A research which was conducted by Mitchell and Martin (1997) found the evidence how chunks are broken down and new words substitute some parts of the chunks as children struggled to express meanings. This evidence shows that once children noted the pattern of the chunks of language and are able to reconstruct it meaning they provide a valuable resource for developing grammar, as they are broken down and re-constituted.

According to Pinter (2006), deliberate teaching of grammar is necessary at one stage to establish and automatize the new-language on the leamer's memory so that when needed they are easily retrieved. However, providing learners opportunity to use the pattern in meaning-focused situation is equally important 
where they get the experience of selecting, using, and revising the language. Teacher has to make sure that the activity is fun for children, not merely repetition. Use games, songs, or project work to recycle the use of the patterns they have learned before.

One interesting idea in teaching grammar to children is using story. Children are usually fascinated by stories especially the fantasy. Using stories, teacher can introduce sentence constructions and tenses such as.imperative, interrogative.

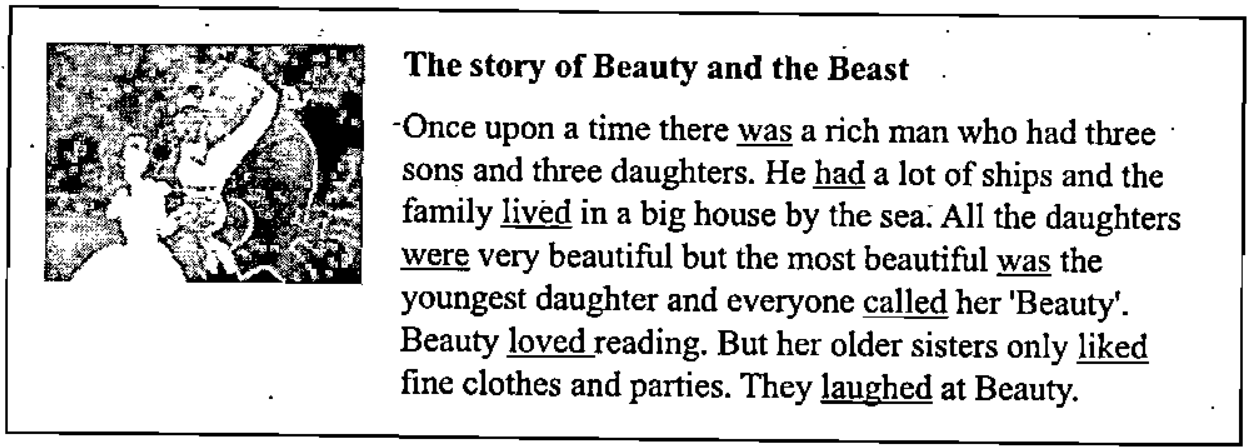

\section{F. Teaching Pronunciation}

Performing correct pronunciation is very important since it will lead someone to a successful communication or fail him. When someone constantly mispronounces some sounds, it will make other people misunderstand what he/she says or get confused. For instance, in a restaurant where a diner is supposed to order soup, he/she is taken as ordering soap instead. Mispronouncing certain sound will not be the only problem a learner has. Putting wrong stress or using wrong intonation pattern can lead to misunderstanding too. As an illustration, when someone makes a request like "Do you mind if I Open the window?" where he puts the stress on the word 'open', a native speaker will think him as being rude because normally the stress will be put on the word 'window'. When the stress is put on 'open', the native speaker may interpret it as the second request and probably is said with little impatience.

Pronunciation is not solely a matter of articulating individual sounds. It covers individual sounds and consonant clusters; syllables and stress; weakly stressed and strongly stressed syllables in.words; how stress works in phrases and 


\section{Negative auxiliaries don't, can't .I can't catch you.}

appear.

Negation 'spread' some becomes

Fraser don't want no food.

no.

negative element inserted correctly I don't want any food.

no changed to any.

Lewis in Brewster (2004) breaks down grammar into three accessible and manageable categories:

- Facts: there are many exceptions in English grammar such as irregular past form of verb, irregular plural nouns that children can only accept for what they are and learn them.

- Patterns: teacher should help children to be aware of the language pattern. Understanding the pattern, children will be able to construct new sentences themselves. For example, I like (ice cream/candies/cakes).

- Choices: A grammatical structure to be used to express an idea is personal choice. We can say either I have drawing since I was 5 or I have been drawing sinceIwas 5.

\section{E. Learning Grammar in Class}

One way to teach grammar for children is through formulaic phrases or chunks. The strategy can both develop communicative skills and grammar mastery (Weinert in Brewster, 2004). Chunks, learned by rote, are sometimes split up into parts and combined or substituted with other words in a sentence. Aresearch which was conducted by Mitchell and Martin (1997) found the evidence how chunks are broken down and new words substitute some parts of the chunks as children struggled to express meanings. This evidence shows that once children noted the pattern of the chunks of language and are able to reconstruct it meaning they provide a valuable resource for developing grammar, as they are broken down and re-constituted.

According to Pinter (2006), deliberate teaching of grammar is necessary at one stage to establish and automatize the new-language on the leamer's memory so that when needed they are easily retrieved. However, providing learners opportunity to use the pattem in meaning-focused situation is equally important 
where they get the experience of selecting; using, and revising the language. Teacher has to make sure that the activity is fun for children, not merely repetition. Use games, songs, or project work to recycle the use of the patterns they have learned before.

One interesting idea in teaching grammar to children is using story. Children are usually fascinated by stories especially the fantasy. Using stories, teacher can introduce sentence constructions and tenses such as.imperative, interrogative.

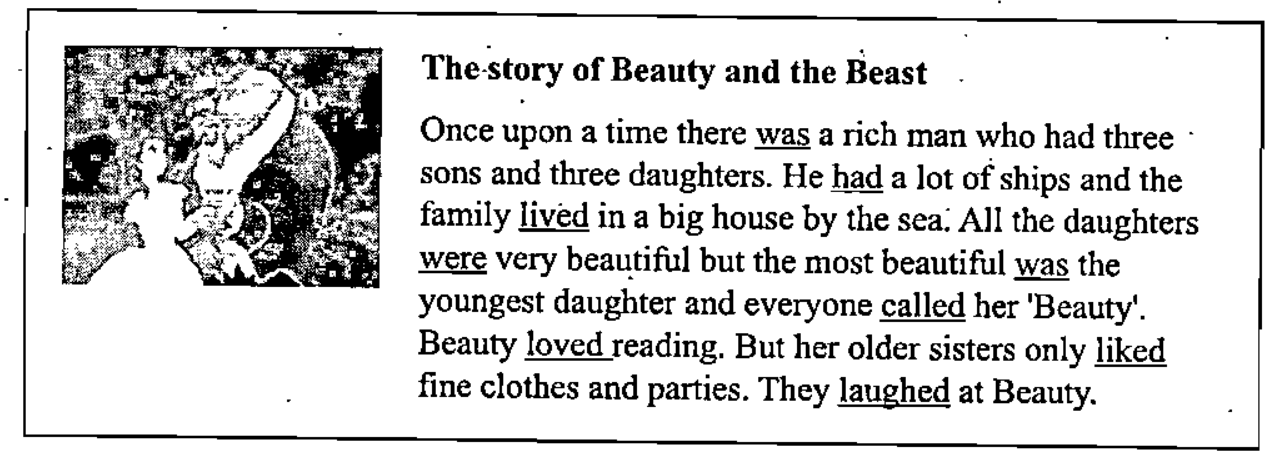

\section{F. Teaching Pronunciation}

Performing correct pronunciation is very important since it will lead someone to a successful communication or fail him. When someone constantly mispronounces some sounds, it will make other people misunderstand what he/she says or get confused. For instance, in a restaurant where a diner is supposed to order soup, he/she is taken as ordering soap instead. Mispronouncing certain sound will not be the only problem a learner has. Putting wrong stress or using wrong intonation pattern can lead to misunderstanding too. As an illustration, when someone makes a request like "Do you mind if I Open the window?" where he puts the stress on the word 'open', a native speaker will think him as being rude because normally the stress will be put on the word 'window'. When the stress is put on 'open', the native speaker may interpret it as the second request and probably is said with little impatience.

Pronunciation is not solely a matter of articulating individual sounds. It covers individual sounds and consonant clusters; syllables and stress; weakly stressed and strongly stressed syllables in words; how stress works in phrases and 
sentences; how stress is used to contrast things; how stress is used in sentences to change their meaning; how the sounds in some words are joined up and link together in phrases and sentences; how intonation is used to refer to old information; how intonation is used to refer to new information; and how intonation is used in question tags (Brewster, 2004).

Many studies about the order of acquisition of classes of sounds characterized by manner of articulation reported similar sequence of acquisition: nasals, glides, stops, liquids, fricatives, and affricatives. Natural classes characterized by place of articulation features also appear in children's utterances according to an ordered series: labials, velar, alveolars, and palatals. This explains why many or even most children can utter mama earlier than other words (Fromkin, 2000).

Furthermore, as we notice, there are always differences in the pronunciation between $\mathrm{Ll}$ and English. There may be vowel or consonant sounds in English which are not present in learners' LI or the other way around, for example, in English there are $/ \theta /, / \partial /, / \delta /$ that are not present in Indonesian. The differences can create problems. It is necessary for the teacher to demonstrate how the sound is produced, for example, how open or closed the mouth is, how rounded or spread out the lips are. The teacher can give exercises that will focus children on the sounds they find difficult. The teacher should also make the children hear sounds and are able to identify whether the sounds are the same or different. The teacher can introduce minimal pairs to develop children's sound awareness.

\section{G Learning Pronunciation in Class}

In reality, English in spoken form is run on together so that it flows. The speaker will not say the words as separate units. There will be sounds blended together. Hence, pronunciation teaching should not concentrate only on the pronunciation of individual sound. To drill children on how the sounds in some words are joined up and link together in phrases and sentences, the teacher can give action rhyme (Brewster, 2004):

Chop, chop, choppity-chop. Cut off the bottom,

And cut off the top What there is left we will

Put in the pot: Chop, chop, choppity-chop. 
Using such activity, the teacher can show how words ending in a consonant sound links up with the next word if this begins with a vowel sound e.g. cut off, there is. Linking the words in this way helps to keep the smooth flow of English.

Besides rhymes, songs and jazz chants are other excellent way in which stress and rhythm work in English. Children's attention can be drawn to the words that usually are given the main stress i.e. content words such as nouns, verbs; adjectives, and adverbs. When a word is stressed, three things tend to happen: the stressed word sounds slightly louder than the others, the vowel in the stressed word is clearly pronounced; and so tends to sound longer (Brewster, 2004).

One important aspect that teacher should put into account is illegibility. It is important in pronunciation teaching-since the goal is that learners' utterances will be understandable and sound well enough for native speakers to understand even though there may be signs of a foreign accent. The problem is in many schools in Indonesia, the only model the children have in class is the teacher who does not always achieve reasonable level of intelligibility. The teacher can actually provide the children course book, which comes complete with cassettes or CD-ROMs that can give good speaking models. If it is not available then the teacher has to work hard to practice and drill himself in pronouncing words, phrases or expressions they are going to use in classroom in order to give good spoken model This practice will be reliable when the teacher works together with another person who has good command of English so that (s)he can correct wrong pronunciation. Here is one example of material to learn the sound $/ \mathrm{s} /, / \mathrm{z} /$ and $/ \int /$.

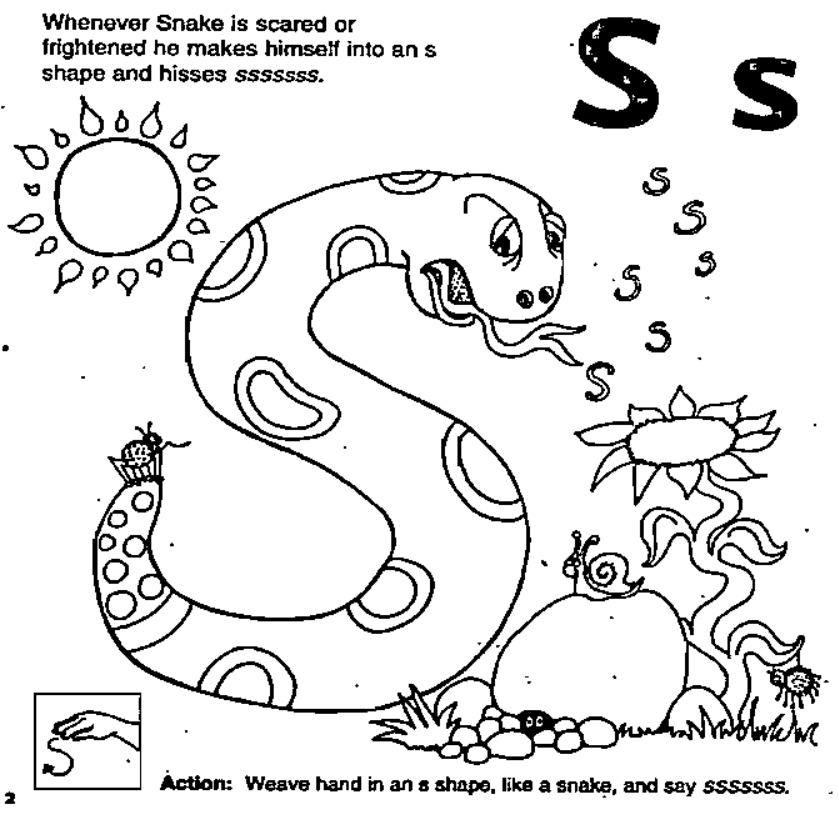




\section{$\mathrm{H}$ : Teaching resources}

Accompanied by sufficient budget, lessons organization is easier. Good books, software, teaching media are available at markets. However, for those with unfavorable condition, our surroundings can be a real abundant resource for the English teaching-learning in class. Used magazines, calendar, cardboard can be teaching media. Besides, many web sites in the internet also provides more than we can take for free.

\section{Conclusion}

Teaching children English language must consider various things. To start with, teachers have to decide what they have to teach. Each of the language - elements needs carefil preparations. The next is how the teaching should be conducted in class. There are basic principles that the teachers should put into account including children's learning characteristics, the nature of each of the elements, and how the teaching can be fruitful in helping children cope with foreign language.

Teaching vocabulary, teacher should firstly decide what 'word' he will teach since vocabulary comes in different forms. Teacher can start it with content words and demonstrate them using concrete objects, pictures, gestures and others in which children can explore them using their senses.

Formulaic expressions and language chunks are considered more suitable to introduce English grammar. By splitting the chunks up, children can analyze the parts and somehow they are able to re-constitute words to create new expressions. Teacher should organize the teaching in such a way that grammar will not be too difficult for children. Children should start learning from the easy one to the more complex constructions.

Pronunciation teaching is not merely drilling children individual sounds. It also should cover stress and intonation. Teacher should also encourage the use of. connected speech so that a sentence or utterance sounds natural. The main problem in teaching pronunciation is that sometimes the teacher as the only model in class lacks of intelligibility. If it is so, cassettes and CD-ROM. 


\section{Bibliography}

Brewster, J. Ellis, G and Girard, D. (2004). The primary English teacher's guide. Harlow, Essex: Penguin Books Ltd.

Cameron, L. (2001). Teaching languages to young learners. Cambridge: Cambridge University Press.

Fromkin, V., Blair, D., and Collins, P. (2000). An introduction to language (Fourth edition). Marrickville, NSW: Harcourt Australia Pty Limited.

Kelly, G. (2001). How to teach pronunciation. Harlow, Essex: Pearson Education Limited.

Linse, C.T. and Nunan, D. (ed). (2005). Practical English language teaching: Young leamers. New York: McGraw-Hill Companies, Inc.

Nation, P. (2001). Learning vocabulary in another language. Cambridge: Cambridge University Press.

Nation, P. (2005). Teaching vocabulary. Asian EFL Joumal.

Pinter, A. (2006). Teaching young language learners. Oxford: Oxford University Press.

Thornbury, S. (2002). How to teach vocabulary. Harlow, Essex: Pearson Education Limited.

Wilson, A. and Scanlon, J. (2005). Language knowledge for primary teachers. London: David Fulton Publishers Ltd.

\section{Online resources}

http://www.britishcouncil.org/kids-stories-football-crazy.htm http://www.eslkidslab.com/flashcards/set1/name/index.html 